\title{
Intersecting social structures and human actors: Ganfoso refugees' settling experiences and impact on children's education
}

Beatrice Akua-Sakyiwah (1)

Correspondence: bakua-sakyiwah@ gimpa.edu.gh; b.akuasakyiwah@ gmail.com

Gender Development and Resource Centre, School of Liberal Arts and Social Sciences, PO Box AH50, Green Hill Achimota, Accra AH50 GIMPA, Accra, Ghana

\begin{abstract}
The myth that Ghana is stable and peaceful, cause many refugees from across Africa and elsewhere, escaping wars from their countries to flee there. Whilst here, refugees face transitional problems in acculturation and settlement, stemming from a lack of education, as many have not had formal education before coming to Ghana. The problem is worsened by an immigration system and a social structure that delays responding to refugees' needs. With a lack of viable employment to support parents' settlement needs, these cumulatively function to affect refugee children's

educational attainment. Using ideas from Giddens' structuration theory as a conceptual framework, the research seeks to understand how immigration rules and other mediated rules at the Ganfoso Refugee Camp, interlacing refugee parents' acculturation/settlement experiences, impact children's educational lives. The article uses narratives from teachers/head-teachers, refugee camp management, and a cross-section of community members to highlight how social structures, policy regulation and implementation, combined with issues of refugees' agency (personal experiences and responses to situation), impact upon their settlement and affect their children's education.

Through qualitative interviews with 69 participants, the article highlight discussions on the effect of institutional barriers to refugees' experiences, and impact on educational access of refugee children in Ghana.
\end{abstract}

Keywords: Structuration, Education, Refugee, Personal agency, Human actors, Intersection

\section{Introduction}

Refugees resettlement is part of the protection that destinations governments are expected to provide victims who escape to their shores. Nonetheless, the complexity involved in their escape results in challenges for destination countries and asylum seekers themselves. Besides struggling to maintain a balance between offering protection to these displaced people, countries also struggle to offer the socio-cultural political and economic resources that ensure smooth refugees' settlement (Agblorti, 2011),

(c) The Author(s). 2020 Open Access This article is licensed under a Creative Commons Attribution 4.0 International License, which permits use, sharing, adaptation, distribution and reproduction in any medium or format, as long as you give appropriate credit to the original author(s) and the source, provide a link to the Creative Commons licence, and indicate if changes were made. The images or other third party material in this article are included in the article's Creative Commons licence, unless indicated otherwise in a credit line to the material. If material is not included in the article's Creative Commons licence and your intended use is not permitted by statutory regulation or exceeds the permitted use, you will need to obtain permission directly from the copyright holder. To view a copy of this licence, visit http://creativecommons.org/licenses/by/4.0/. 
and Ghana is no exception. Ghana has a long history of attracting refugees to its shores, comes as a results of proven records of peaceful and stable environment (UNHCR 2012).

Whilst in Ghana, most of the asylum seekers settle in Ganfoso Refugee Camp, believe to be a place where settlement is processed easily and quickly (Akua-Sakyiwah, B (2015): Refugee Education in Ghana, unpublished). As a result the camp is one of the largest settlement for refugees and asylum seekers, housing about 15 nationalities, from countries across Africa and Asia: Chad, Somalia, Sudan, Sierra Leone, Rwanda, the Democratic Republic of Congo, The Central African Republic, Togo, Ivory Coast, Ethiopia, Burundi, Uganda, Congo Brazzaville, Liberia, and Pakistan (Akua-Sakyiwah, B (2015): Refugee Education in Ghana, unpublished). Due to its diverse nature, the camp is described as "a melting pot of cultures, religions, passions, dreams, languages and dialects of Africa, English, French and Arabic" (Kpatindé 2006).

For asylum seekers who have fled to Ghana, learning to function in their new environment and to integrate smoothly is challenging, particularly, as they face vigorous process of determining their legitimate claim. Besides this, their experiences and movements are governed by immigration rules that restrict access to social resources that should facilitate easy settlement. Employment for instance, has been seen as helping refugees integrate smoothly. According to Valtonen (2004), employment determines a person's level of integration. With the acquisition of material resources gained from employment, refugees are able to build other 'social capital' that gives them access to the wider community (Valtonen 2004, p. 3). Participation in employment has also been seen as helping refugees have contacts with groups outside their immediate community and establish networks that reinforce continued relationships with other people within their place of domicile. However, as shall be discussed below, a limited access to social resource, and the deprived geographical location of Gunsofo camp, for even farming, results in a lack of job opportunity leaving refugees at Gunfoso camp in severest poverty. As a result, they struggle to survive. Some have been promised durable solutions and for years nothing is told them. Others have waited long for their immigration claim and for years they have seen no results. Yet others who have been offered refugee status, find life outside the camp threatening and so have remained in the camp for years.

\section{Literature review}

Saturation theory has been used in diverse ways to study refugees' situation. In 1993 for instance, Richmond (1993) used it to investigate refugees' movements. Similarly, in 2001, Al-Ali et al. (2001), examined the capabilities of refugees to partake in transnational connections, through structuration theory. Healey (2006) too applied employed it to theorise refugee studies by examining the narratives and experiences of asylum seekers and refugees in the UK. The theorist conceptualised how asylum-seekers and refugees utilise coping strategies to raise their comfort level in the host country. Again, in 2010, Naidoo (2010), applied the theory to explore refugee students' literacy developmental needs. The studies suggest that asylum seekers and refugees' diverse experiences that impact their integration, are affected by structural and individual agency factors. In the UK, Healey noted that the structural (consisting of public and political) reaction towards the increase number of asylum applications, was met with a reactionary response, in which the agency (asylum-seekers and refugees) resorted to social networks for a sense of security. In this study Healey noticed that structural factors impact immensely 
upon the integration of refugees and asylum seeker. She argues that negative experience creates anxiety and insecurity amongst asylum seekers and refugees, whilst positive experience increases their sense of wellbeing.

Refugee integration and settlement issues have been a global phenomenon and many governments face policy challenges in dealing with these. In many instances, this results in increasing number of protracted refugee cases, with many happening in Africa (Agblorti 2011). In recent years the willingness to accept refugees in destination countries has been hampered due in part, to the assumption that refugees are temporal guest and will be leaving back home as soon as conditions normalises in their home country. However, the severity of disintegration of their home country, which prolongs stability, often makes return impossible. This particularly affect most refugees who do not qualify for both local integration and settlement solution. In such a situation, since these refugees are not recognised by the host country as refugees, they are not able to participate fully in economic, socio-cultural and political spheres in the host country. Local integration has been recognised by scholars and nongovernmental organisations, as a workable durable solution for refugees (Valtonen 2004), especially those in the global south. In particular, where voluntary repatriation is not an option Jacobsen 2001). However, due to a lack of policy clarification, it results in vague definition, and success of local integration has been left to the discretion and willingness of host governments (Agblorti 2011).

After attaining recognised status, refugees struggle to learn both English and the native language to facilitate their smooth settling. This language barriers and home patriarchal experiences create transitional problems in acculturation and settlement for refugees who may not have been to school before being displaced. Research indicates that refugee children are among the highest number of the displaced persons in the world (UNHCR 2013).

\section{Anthony Giddens' theory of structuration}

In his 1979 collection of essays, Giddens frames his core concern about the inadequacy and lack of accuracy of 'interdependence' in the discussion agency/structure divide (Little, 2012). Giddens assumed that the concept of structure/agency is flawed without theorising "human agent", and "accounting" for the "conditions and consequences of action", and without "interpreting structure" as embodied "conditions and consequences". He differentiated between structure, systems and structuration. Giddens sees structure as rules and resources, organised as aspect of social systems, existing as "structural properties" (Healey 2006). According to Giddens, "systems" are organised in a routine social activities which "produce relationships" between "actors". Structuration on the other hand, is the "conditions governing" the continuity, or the "transformation of structures that reproduce the systems" (Turner 1986). Giddens use action and agency interchangeably, not to refer to a series of combined activities, but as a continuous flow of conduct. He explains that actions take place in contexts, adding on to the actions of others, includes the constraints and opportunities that social structures create (Little, 2012). By this, head another dimension of action that involves forms of knowledge that actors possess to help them to channel their "interventions". 
It is the theory's analyses of the relationship between structure and agency that gives significance to the refugees' experiences discussed in this article. Of particular interest here is his conceptual consideration of power, identities, contexts, and social systems and the way they affect human actions and cause them to reproduce the very structures that influence them. Giddens sees structure as a virtual order without physical existence, but revealed through every day human activities, governed by rules and regulations; Bill of Rights, policies, organisational practices, and the use of social resources (Sewell Jr. 1992). This includes the use of material allocation, command over objects, goods and services, and command over persons or actors (Giddens 1984). According to Giddens, these are external constraints that affect human actions to create meaning. Though not seen, they present in our social interactions, and informs and sustains our behaviour.

Refugees' experiences are mediated through immigration rules and regulations and the laws of the land, and it is these that direct their actions and dictate the outcomes of their existence as refugees. As refugees interact and work through these mediated structures, they help to reproduce the very structures that impact upon their action. Giddens calls this 'duality of structure' and it offers perspectives on the relationship that human agency has with the structures they find themselves in. Anthony Giddens' concept of saturation, was prevalent in this research findings. The roles of the camp management, teachers and headmaster are all governed by rules that both restrict their actions and allow them to police events. By this they helped to produce specific outcomes that creates interactional problems for refugees who do not see rules, but external human actions. They rather blame management and schools for their plight and those of their children.

According to Giddens', structure evolves with social interactions to create change. $\mathrm{He}$ describes human beings as "purposive agents" (Ma 2010) who are aware of the intended outcomes of their actions. This awareness becomes a reflector that monitors their everyday routines (Giddens 1984, p. 4), thus creating a context for mutual relationship between agency and structure, ordered across space and time. This mutuality further creates a setting for reproducing and maintaining structure. This understanding is significant for what goes on at the Ganfoso Refugee Camp. It is the co-presence and the interactional dynamics between the various actors: the camp management, refugees, teachers and other agents, operating within a given regulatory framework that feed back into, and maintain the social structure. This is discussed below.

\section{Methodology and research approach}

The theoretical framework that undergird this discussion is the agency/structure debate, which is central to determining social phenomenon, social structure and individual actions, also known as human agency (Dowding 2008). Agency refers to beliefs and desires of the members by which their actions are explained. This includes the rules of the institutions involved and the actions that members are expected to exhibit in a specific context (Varelas et al. 2015).

In this article, agency refers to the individual's experiences and actions that are volitional and purposeful, but which are also triggered by the operation of structure. Structure on the other hand, are the immigration rules, as well as human mediation rules that govern the lives and activities of the refugees in the camp. The human mediation 
rules are those added rules designed by the camp management to monitor the everyday lives of the refugees. As shall be discussed later in this article, these rules, often operating outside, but in compliment to the immigration rules, combined to determine the fate of the refugees.

The analysis draws on an empirical, qualitative study of Gunfoso refugee camp and the community school situated near the camp, which also serves both the refugee camp and the neighbouring Ghanaian communities. Though the school, which is a mainstream public school, is expected to serve both native born Ghanaian and refugee children, due to its close proximity to the camp, and its distance away from neighbouring Ghanaians, refugee children form the highest population. The refugee camp was also chosen for its mix of refugees from different countries in African and elsewhere. It has the largest population of refugees with diverse cultural background. This makes it a culturally viable location to sample views from differing backgrounds whose experiences can be compared. Situated east of Nangroso and south-west of Afumso local community village, the camp provides a place of safety for refugees deemed as "highrisk group". Gunfoso camp is isolated from other communities within the area. It lacks industries or other income-generating activities and it is deprived of both social resources and links to neighbouring Ghanaian communities. It's geographical remoteness, and lack of social resources, combined with their experiences as refugees, make the place a suitable place to undertake a research that explore how refugees experiences impact on their children's education. This helped to present a diagnostic analysis that could be a representational to other similar refugee locations in Ghana and elsewhere in Africa.

Purposive sampling was used to select participants through snowball approach. By this I was able to select participants who are concerned with the welfare of children, including parents, the students, teachers/head-teachers, refugee camp management, and a cross-section of community members. Significance was placed on the reported experiences of these persons. The adoption of narratives was to allow informal conversation approach where participants flow freely in their story (Easby 2016), with a few probing questions to solicit clarity, and as a way of directing the research focus. I also observed pupils aged 6-12 (Primary years 1 to 6 ) in their classrooms to see how their interactions with peers and teachers facilitate their learning. The purpose was to gain an insight into some of the things that hinder, and/or enhance students' ability to cope with the classroom situation.

The research instruments were mainly interviews and documentary review, done through focus group and face-to-face interviews. I also reviewed reports and documentations on refugees' experiences in Ghana. In this article I only drew upon the interview data. Responses to how interview approach allow participants to narrate their own stories was significant in achieving the research theme. Research on how structural systems influence refugees' behaviour and vice-versa, influence the themes that informed the data collection.

The interview was conducted following a thematic pattern, framed by a pre-prepared topic list. This allowed the interviews to produce data on the main research themes. These were later classified and coded, and the process helped to identify emerging themes. The aim was to look for traces of refugee settlement and how this reinforce their experiences and those of their children's education, including how literature 
address their needs. It was noted that refugees' experiences have been extensively written on, but not in the way that these, combined with immigration rules impact their children's education. This did not only enhance understanding on the main research topic, the classification became useful as they reflected the data collected.

The theoretical analyses of the data were based mainly on Giddens; structuration theory.

In this research, the theory of Structuration was appropriate in understanding the dynamics involved in human interactions as they interlace with structures to produce specific defined human behaviours. This is in line with Hay (2009) assertion that the structure-agency debate enables interpretation of empirical investigation to be made. Analysing refugees' experiences through the lens of this concept is important, because participants' narration mirrored how the designed immigration rules and regulations, govern the daily lives of refugees, and this reflected the concerns raised.

Ethical consideration was critical and the individuals who participated needed assurance on the preservation of their confidentialities. Since the research field was a refugee camp where various restrictions exist, I sought clearance from the Ghana Immigration Board, to enable me access the camp, and take stories from the refugees. With this, the camp management allowed me full access to the camp, including refugees' shelters, where I lodged for a period of 2 weeks. Many of the interviews took place in the shelter where I resided. Some in the homes of families, and others happened in open spaces, community centre, etc. The interviews conducted in schools took place in the staff common rooms, office of the heads of schools, empty classrooms, open spaces, etc. This allowed as many people as possible to participate in the research. Many of the refugees who took part were of the view that I was a government official who is there to help solve their immigration problems. As a result, I had to reinforce my initial statement that the research is purely for academic purposes. Snowballing approach was adopted and this was very useful, as participants signposted me to relevant people I could interview. The dynamics of the discretion and voluntary nature, as well as the objectives of the research were all explained to participants, and options given them to either opt out or participate.

The Research from which this article was written was conducted in January, 2015.

\section{Analysing the data}

\section{The situation at the CAMP}

Giddens' exploration of the theories of social systems reflects the ways in which individual activity is affected by, and has implications for how things are organised and people's interaction to them. It is this that particularly links discussions of the refugees' experiences to Giddens' structuration theory. This is because the everyday operations and functions of refugees/asylum seekers are culturally, socially and organisationally structured. It is within such structured systems that services for refugees are framed and dispensed. Professionals working within the immigration setting are limited by the rules and regulations that govern their operations. This results in delays to services and in many cases such services never surface. Such constraints also allow certain operations to erupt within the dynamic system where human agents adopt particular strategies to meet the needs of refugees, but often these are biased towards others. For 
instance, participants informed me that, due to acute shortages of resources, including food, refugees who are resettled abroad try to send them food and other useful materials. However, these items are only given to a few favourites, or are diverted elsewhere and never get to the camp. The nature of immigration rules disempowers refugees and denies them the ability to articulate their concerns as explained by Mrs. Ansomana:

Our views are suppressed and everyone is afraid of being targeted and victimised if they speak out. Life at Ganfoso is a living hell. I arrived at the camp in 2004, with a four-year-old son. But to date we residents are unable to voice why access to our rights is denied us and why our dignity and respect as human beings are trampled upon. (Ansomana)

Giddens (1984) asserts that an agent has the capacity to influence a change, lacking this capacity limit their ability to act. From the perspective of this woman, and many other refugees I interviewed, lacking the voice to articulate their concerns has affected their well-being and those of their children. Many participants raised concerns that people who attempt to speak on their behalf are treated as criminals, that the camp management uses the police to intimidate them. Their narration suggest, the camp management has control over both authoritative and allocative resources. Therefore coordinate human activities and regulate material products. They decide who are offered access to skills training and other opportunities. As a results, when instructions are issued for people to be selected for training, the management select those they favour. The participants claim that recommendations for durable solutions are left to the discretion of the camp management and it is on the basis of such recommendations that selections are made. As a result, the camp is divided into two factions: those who support the management because of the incentives they gain from them, and those who do not, causing refugees to fight and create divisions among themselves. Those in support connive with management against others and fabricate misinformation in order to gain favours. Such divide and rule tactics create disunity.

An idle JHS graduate, who left school 2 years ago, summed this up as follows:

Ganfoso is a small refugee camp, but you have no idea what goes on here. It's like boiling water, too unbearable for the bubbles (the molecules) to stay together. That's why everyone tries to escape. The life situation here is terrible and people are not necessarily getting on well. There are too many things that are hidden from the eyes of people like you [referring to me, as a researcher]. (Anton).

In the words of Ada:

This camp is small but it feels like we live in a chaotic world, there is no peace in Ganfoso. (Ada)

Comments such as these illustrate a situation that needs urgent mediation. According to Giddens, structure is implicated in all social interactions because they are dependent upon rules and resources. We see from the refugees' narration that 
some people are manipulating the structure to suit their personal interest, to the detriment of the refugees' welfare. Again, the structure offers authoritative powers to the camp management to govern, and subject the refugees to obey rules. In so doing they recreate a structure that suits their operations, as indicated by Giddens (in Inyundele (n.d.)).This is true to the way that supporters of the camp management experience rewards, and others suffer for not adhering to the status quo. These actors are motivated to rationalize their operations to give them a sense of security. Giddens call this "ontological security" (Giddens 1991, pp. 35-42).

\section{Geographical location of Ganfoso and its effect on refugees experiences}

Ganfoso refugee camp is isolated from other communities within south-western part of Krunso. Lacking industries or other income-generating activities (only a few people sell groceries or cooked foods), the camp is deprived of both social resources and links to neighbouring Ghanaian communities. The residents walk for several hours to neighbouring villages and towns to purchase their requirements, including food. This makes Ganfoso, a very remote environment. Some of the people I interviewed commented that they feel they have been banished to a place where nobody cares:

At Ganfoso, we feel as if we are being punished for being here. It feels like being in exile. When I first came, everybody said that Ganfoso is good because it's a place for a quick transition and everything goes fast. I also thought that because people come from all over Africa and elsewhere, it will be a good place to meet different people. But the disappointment you get when you come to this camp is huge. Nobody cares what happens to us and life seems very hard. At least if somebody cares then we know that one day someone will do something. (Mr Brason)

Mr. Brason is distressed about unmet expectations at Ganfoso camp. Having been informed that Ganfoso refugees go through a fast transition period, lingering here, isolated and with virtually nothing to do, frustrates him. His narration reveals that his experiences here have added to the trauma he experienced in the war zone that brought him to the camp in the first place. Feelings of isolation, neglect, deprivation and disappointment show on the faces of all the people I interviewed. Throughout the interviews they admitted that not being able to speak the local dialect makes it difficult to interact with the local community, and they found it hard to do things without support from the UN or the Ghanaian government. A few who had been offered local integration expressed the difficulty of integrating with people who seem to reject them:

If I have to integrate then it has to be with people who want me to live next to them and among them. It feels scary and disappointing to even think that I'm now having to begin to learn a vocabulary that the originators don't want me to be a part of in the first place. And for the years I've lived in Ghana, I would have learnt the language if these people were friendly, and if the camp were in the right location. (Adriane) 
The views expressed by Adriane is in line with literature assertion that over the past decades African' solidarity, hospitability and willingness to accept refugees have been illusive (Agblorti 2011; Frelick 1997). Such views prevent refugees from engaging in the proposed local integration that the Government has offered them. During the interview, it was noted that many who have been offered local integration but have refused. Others who have accepted this were still living in the camp, afraid to move out for the fear of the unknown. A refugee's freedom to settle and manoeuvre depends, to a large extent, on the stabilisation of their immigration status. When this decision is delayed, it affects their ability to function effectively in their host country. Many of these refugees share such experiences, as Mumbahu explains:

In 2008 I was interviewed for the resettlement programme as part of the durable solution offered by the UN. I was told that I had been accepted and that they would get back to me. Since then I haven't heard anything about this again, but several people who came after me got their resettlement and left, and I'm still here at Ganfoso, struggling every day and wondering each passing day about what life will bring. My son finished JHS and is just wandering about with no money to help him further his education and no job. Is this what they call life?

Many of the people at the camp are either asylum seekers, have received refugee status, are on an exceptional decision that qualifies them for the UN durable solution programme. Some have been in the camp since 1996; others arrived more recently. Many are still awaiting a final decision on their claim and many complained that they have only been interviewed once even after several years of being in the camp. A common perception is that the immigration authorities have forgotten about their existence and that resettlement to other countries favours new arrivals over those who have been in the camp for years, though many of them have accepted resettlement, they are yet to see the real fulfilment.

A discussion with the protection officer for refugees at the UNHCR, however, revealed that resettlement to western countries is the prerogative of the receiving country and that neither the UN nor the Ghana Refugee Board has any authority over their decision. However, these refugees do not seem to have been educated about this, and lack of understanding is creating stress among those who have been promised of resettlement.

For other refugees, the fear of living alongside their wartime opponents causes mental instability. For instance, one worried asylum seeker, Ario, expressed fear about mingling with some of the opposition faction from his country and expresses real danger.

My language and religion are a target for war. I feel very unsafe even at my place of refuge and though I have complained and reported this to the camp management, nobody does anything about it. But every day I feel like I'm still being haunted and on the run from my own country. I can't bear this trauma, even though I try to. (Ario)

The signs of emotional trauma and unstable mental state immediately become obvious to anybody who approaches Ario for the first time. He has been subjected to 
torture and trauma at the hands of the opposition faction, and to meet such people and mingle with them in the same camp creates further stressors that add to the Post Traumatic Stress Disorder (PTSD) that he and many fleeing refugees experience (Akua-Sakyiwah, B (2015): Refugee Education in Ghana, unpublished). However, no counsel has ever been offered to Ario, and every day at the camp he feels anxious about what will happen to him next. Unfortunately, Ario is not the only refugee going through the trauma of war without support. Most of the refugees are experiencing increased stressors and high PTSD levels.

Discussions below explores and traces the inter-relationships between structures and obstacles to parents' socio-economic defence. It highlights how a lack of access to social resources impedes children developmental well-being and consequence negative results.

\section{Access to resources}

Residents at Ganfoso camp have little access to social services, including employment, healthcare, etc. Housing for refugees is not always equipped with the essential facilities, making life very uncomfortable. For instance, I visited a family with five children: three grown-up boys and two girls. Including their single mother, making a family of six. This family lives in a two-bedroom thatched house with an attachment of a kitchen and bathroom made with bamboo and palm leaves. These thatched houses have no toilet facilities so families, including little children, ease themselves in the bushes. Mothers and fathers are not always at home, and children, including girls, go to such places unaccompanied. They mentioned that this exposes them to dangerous reptiles, and girls are exposed to rapists who are using the poverty and hunger at the camp to lure vulnerable little girls. But the management at the camp, acting in accordance to immigration rules, refused to allow the Residents the permission to dig a pit latrine at the camp.

A visit to the home of one family revealed the horror of the effects of hunger and poverty at Ganfoso refugee camp. Asma is an eight-year-old girl, and on her way to school 1 day, a male predator enticed her with money and raped her in the bushes near the school. From the family's narration, Asma's private parts are badly affected; to the extent that when she passes urine the smell it produces is unbearable, requiring plenty of water to wash off the unrine. The rape left sever pain and caused damage to Asma's private parts. She no longer attends school because she cannot sit without wetting herself, and could not deal with the horror of taking the same rout. There was an indication from what Asma's parents said that the local hospital did not have the right equipment to deal with Asma's medical needs. However, all attempts to get the doctors to refer this child to the right hospital for appropriate medical treatment failed to yield a positive response, because they must also act in accordance to certain immigration regimes. The parents are afraid of what may happen to their daughter.

My husband and I have been having sleepless nights about our daughter's predicament, which does not seems to stop anytime soon. Several times we have requested that they transfer my daughter to the right place for proper 
medical attention, but no one seems to be listing to us. . When she is in pain, the clinic gives us pain relief. Sometimes they prescribe medicine for us to go and buy, but how? With no income, it is difficult to buy this medicines (Asma's Mother, speaking on behalf of Asma).

Delays in refugees' request has almost become the norm according to the refugees. Many of their narrations suggest that such delays affect their situation in so many ways. However, unknown to the refugees, service providers also operate under strict rules that regulate what they do and many times this slow down their operatives. The requirement to pay certain medical bills whilst on the NHIS is part of the laws of Ghana, which affects all Ghanaians. But a refugee with no access to financial resources or support cannot be made to meet obligations that are impossible. Though this puts their lives at risk, it is a rule that also binds all Ghanaian citizen. The UN Convention expects member countries that have signed up to provide health facilities for arriving refugees (UNHCR, 2014; Convention on the Rights of Children, article 24 (1)), because they tend to suffer from various illnesses due to having passed through different border countries before arriving at their final destination.

The Structures of UN Convention that define the rules, work outside the context of member countries' laws. Member Countries depend on what they have and the rules that bind the distribution of resources to function. Such is the dual opposing forces that work in structures. The provision of health services to refugees are restricted by the functions of the health system in their host country, which must also occur within the available resources. This operative structure supersede the request by the UN Convention request for refugees.

Refugees have health problems due to their traumatic experiences, and for most of the children this affect their education. In the case of Asma who suffered rape on her way to school, her health situation has gotten in the way of her studies. Yet, all the agents involved in the education and well-being of the child, including teachers, the camp management, community leaders, parents and health personnel at the camp, have no control over the situation.

Unemployment issues caused severe cases of impoverishment at Ganfoso that affected the educational attainment of refugee children. Since 2008, this situation has worsened because the UN and World Food Programme stopped supplying food support to refugee families. As a result of the lack of farmland to engage in agriculture, creating acute joblessness, the camp residents face persistent hunger (Amposah 2009). This situation continues to affect children in particular, who according to the participants' narration are severely malnourished. The results is prostitution among girls, as a means of meeting the financial needs of families. Others find means of survival, but through some hard gains (Akua-Sakyiwah, B (2015): Refugee Education in Ghana, unpublished). These experiences are reflected in the narrations below:

Many of the young girls in the camp are prostitutes. They do that to support their families. Mothers even expect their girls to bring money (Apanko, acommunity leader)

A single mother undertaking prostitution also narrated her ordeal: 
... As I'm talking now, I'm pregnant, but I have to continue prostituting myself to feed my children (Odunna).

Most of the participants complained about the difficult life at the camp due to a lack of employment. Women burn charcoal to survive, but those who hire them pay only little money. A few of those who employ these refugees are refugees themselves, but the majority are Ghanaian farm owners. Often the women pull their children from school to accompany them in the charcoal burning.

... . Many times I'm hired to burn charcoal but I only get a little money though I may have been there for the whole day. I'm a single parent with children I have to feed? Many times I pull my children from school to help me because I can't do this alone, it is a difficulttask!

Though the work is tedious, but it is the only source of income for most. Again taking their children along causes them to miss class.

Considering the struggle of parents in terms of prolonged asylum decision, socio-economic deprivation and the slowness of immigration authorities to respond to the needs of refugees, it is not a surprise to learn that the advancement of schooling and of academic accomplishments for their children have been hampered. The narratives from participants suggest that a significant number of the young population has never attained such achievements. This calls for a reconsideration of the unequal power relations that agency/structure presents in the situation of refugees at Ganfoso. The paragraphs below discusses the educational struggle of refugee children through the lens of parents' situation. This will be highlighted through the 'Ghana's feed the children program, which again provides another level of understanding to the structure /agency operatives in refugee children's educational lives.

\section{Teachers' responses to refugees' educational needs}

Giddens' Theory of Structuration also provides contextual understanding to the education that refugee children received organised around classroom culture, and teachers' responses to refugees' educational needs. Ganfoso refugee camp has its own community school, created by UNHCR in 2008, but handed over to the Ghana Education Services in 2010 (Schmidt 2016). It caters for refugee children and those from neighbouring villages. In Ghana, the medium of expression for formal education is English, and all the children, regardless of where they come from must conform to this rule. Interviews with students from the Junior Secondary School revealed that teachers use vernacular to explain things when they sense that some of the students have not understood what is being taught. But this only benefits Ghanaian students, leaving refugee students, particularly those from French-speaking countries, to struggle. This is Giddens' suggestion of how structures' interaction with human agency create a particular results. But this is to the detriment of refugee children's education, as in the statement of Aduan: 
It's really painful when we see the teacher explaining things to them (Ghanaian students) in their language, and we haven't understood the teaching as well yet. Only the Ghanaian student benefit (Aduan).

According to the participants, they have raised concerns, but the teachers have ignored their persistent complaints. Educational policy requirements encourage schools to apply local languages to reinforce understanding in learning and teaching, but it has not catered for foreigners like refugees, who may not yet understand the Ghanaian local language. But this language barrier blocks access to educational attainment for refugees. At the primary school, some of the year-six pupils wished for a French-speaking teacher to support their learning. Arguing that there are qualified French teachers at the camp who have tried severally to volunteer as support teachers, but they have been refused. This was affirmed by refugee parents who indicated that there are educated refugee adults, literate enough to be used as teaching support. They have persistently made these concerns known to the school, yet nothing is done about it.

Research by Young \& Hélot (Hélot and Young 2008 cited in Marnitz 2014) has confirmed that a bilingual child benefits more when the classroom is made to reflect their home environment. In a project named 'Didenheim', the writers suggested that the home-school connection is important for the bilingual child's education to cement their understanding of what is being taught in class. Unfortunately, Ghanaian educational settings are not yet resourced to accommodate support staff. Although Ghana's immigration laws permits those who have been given refugee status to study and work (Anarfi 2010), as at 2015, when these interviews were conducted, the immigration rules prevented refugees from teaching, according to the narration. Therefore, despite completing teacher education and being offered qualified teacher's status (QTS) in Ghana, the participants remained unemployed. In his statement, Santos stated:

I completed the Diploma in basic teacher training education in 2014, but I haven't been able to teach in Ghana because the immigration policy doesn't allow refugees to teach. What will I do with my qualification? (Santos)

As a bilingual teacher, Santos could be of immense support to refugee children, who can relate to him better and many parents wished so for their children. What is not clear is why these refugees should be allowed to pay huge sums of money to study courses and gain professional qualifications that they will never be allowed to use. Confirming Giddens' idea that interactions between social structures and human agents create complications, yet this must be sustained by the human actors to ensure the structures' continual sustenance. Refugees have a pool of talents and skills that they could use to contribute to the Ghanaian economy, but this is being wasted in the name of legislation.

The role of Head teachers who are supposed to allow refugee qualified teachers to act as support staff in the scenario above, becomes that of reforming officers who police the rules, and ensure its continuing existence. However, this is done to exclude others, hence Giddens' notion of structure being implicated by social interactions and resources comes to the fore in the refugees' situation described above. The heads teachers 
are aware of the consequences of not permitting these support teachers, but they must monitor and ensure they maintain the status quo.

In Ghana, basic compulsory education ends with Junior High School. After that, education is left to children's parents. Many Ghanaian parents are unable to support their children through Senior High School, which would give them access to Further/Higher Education. For refugee parents, the unaffordability will be doubly felt because, whilst a native-born Ghanaian may have access to support from extended family, and or fall back on the sale of capital assets to support their children, a refugee parent has no such backup. 'Joblessness' at the camp is producing a generation that uses sex and other criminal activities to deal with their situation and cope with their condition. One teacher said:

It's sad to see the lives of these young people, who could have contributed to the Ghanaian economy and to their own individual lives, coming to a standstill and being squandered. Most of them come around here to play football, some prominent scholars. We see them all the time, but what can we do? We didn't make the rules ... (Mr Hardingson)

We hear stories of burglary in the neighbourhood involving these young refugees. Sometimes it breaks my heart, because some are highly intelligent. (Miss Sonia)

Statement such as this suggests how structures can limit human actors' routinised activities.

Teachers, by virtue of their role as reinforcement agents, become part of the human agents that constitute the social structure. Yet, by their behaviour in the classroom, they become the medium through which the rules that govern the constitution are reproduced and strengthened. By this adherence, they become trapped by the constitutional rules, yet they must continue to promote its progress and development. This is a demonstration of Giddens argument that in every action there is the potential for actors to participate in changing the 'rules' or structures through further action. It is clear from this discussion that human's interaction with the practices in the classroom and the rules governing these practices, triggered further actions of exclusion and inclusion that affected refugee children's education.

According to both the teachers and the students I interviewed, hunger is their greatest problem. This is the result of a lack of responsiveness to adhere to the school's plea to pilot the School Feeding Program (SFP) at the school. The SFP is an initiative between Comprehensive African Agriculture Development Programme (CAADP) Pillar 3 and the New Partnership for Africa's Development (NEPAD). The Government of Ghana embraced this initiative as part of its efforts to attain the United Nations Millennium Development Goals (UN-MDG) on hunger, poverty and primary education. The program is designed to provide food for schools that have the highest poverty rate so as to support parents who may be struggling financially (MGCSP 2015). At the time of the interview, the program was being piloted by selected school and Gunfoso public school was not part of this exercise. But teacher efforts to push the Ganfoso school to have this failed. They all blamed 
policies that for limit their efforts and the scope of the SFP, including slow response of those responsible for making changes.

Many children arrive at school without food and so they are not able to focus. They follow their classmates during break to beg for food they buy, and many are mistreated as a result. Sometimes they go home hoping to meet their parents or get food from their neighbours, but to no avail. Parents usually do not leave any food at home and neighbours are equally struggling to feed their children.

Every day my mum says when I come home there will be food, but she means in the evening. In the day there will be no food. Sometimes when she comes home she will cook rice or fry some fish with bread. Today my sister and I never had anything to eat until evening. It's hard to listen to the teacher when you're hungry. (Canedrey)

Almost all the teachers confirmed that hunger seriously affects children's performance and attendance. Many who ask to go during break time do not return. They too raised concerns about the malnourishment effect on the children's education:

Dowding (2008) point out that the structure/agency divide operate within specific contextual power dynamic. The research revealed that often, the operation of structure upon the experiences of refuges, render them vulnerable. For those in Ganfoso, they expressed their displeasure through demonstrations against the camp authority and the immigration authorities. This caused the authorities to streamline situation at the camp and eventually responded to some of their immigration needs.

\section{Conclusion}

This article considered the implications of Anthony Giddens' theory of structuration for Ganfoso refugees' settling experiences and how this, together with other factors, impact their children's refugee experiences and affect their children's education. The effect of human action towards refugees' experience, identified through certain regulatory framework, interlace Giddens' central idea of social relations between human action and structure. At the root of this theory, and crucial to this research, are the social practices that "bite into time and space" (Tucker 1998, p. 85) to enforce social change. Hidden from the eyes of outsiders, the camp officials depend on immigration services to function. They work hand in hand with the $\mathrm{UN}$, which has a responsibility to secure durable solutions for refugees and also to advise the government on issues pertaining to refugees. They too work within specific rules, which are often not fully understood by the refugees. Similarly, teachers depend on specified rules to teach and support refugee children. The effect of poverty on refugees stem from their joblessness, and immigration status which defines what they can and cannot do, limiting their economic viability. The result is their inability to provide for their children. Thus, when it comes to refugees' children's education, one notices that besides, being affected by parents' experiences stemming from immigration and the camp mediated rules, they are also affected by school rules which make it difficult for teachers to render services that would have supported the children. What surfaces from this discussion is the way in which structure affects human actions and restricts moves that will enhance well-being of both refugee parents and their children. This triggered further action that brought structural changes to the rules. Research is needed to ascertain the magnitude of 
human intervention into the rules of immigration and their effect on refugee experiences. It should also investigate the profound effects of human actions upon the advancement of refugee education specifically, and their wellbeing generally, within the context of education and immigrations rules.

\section{Acknowledgements}

I confirm that the attached manuscript has been submitted solely to this journal and neither the whole manuscript nor any significant part of it is published, in press, or submitted elsewhere in any form, including as a working paper, online, in a journal or a book. Consent for Publication is not applicable as all information indicated came directly from the research and all secondary data used are cited and referenced. Consent was sought form the University's Ethical Committee who approved before the research could be done. Again before the interview, I sought oral consent from those who could not read and write. But for those who could, they were encouraged to sign a Consent Form. All participants were assured of confidentiality and the necessary contact numbers were also provided them, should they have any further queries. Also, I was given Entry Consent Letter by the Ghana Refugee Board, however, due to the long time lapse, I have lost handling of this letter.

\section{Author's contributions}

The author, Akua-Sakyiwah, B. carried out the research, and with the support of her teaching assistant, did the transcription. This article has been written solely by the author. However, comments and suggestions were provided by Liz Sourbat, after reading through the the first draft. The author read and approaved the final manucsript.

\section{Funding}

I had no funding source for this research, as a result I applied through your Low Country Policy Scheme for a waiver, which this has been granted me.

\section{Availability of data and materials}

I have indicated in the Methodology section of the article that the research adopted qualitative research methodology through interview approach. I have used and cited some of the participants' responses in this article, and I have also indicated author citation at page 2 of the main document, and the reference lists at page 19 that this research findings are unpublished.

\section{Competing interests}

I also declare that I have no competing interest, and that the research was carried out by me.

Received: 18 November 2019 Accepted: 24 August 2020

Published online: 30 October 2020

\section{References}

Agblorti, S.K.M (2011). Refugee integration in Ghana: the host community's perspective (Research Paper No. 203). UN High Commissioner for Refugees (UNHCR). https://www.refworld.org/docid/4d88749d2.html. Accessed 21 Aug 2020.

Al-Ali, N., Black, R. \& Koser, K. (2001). Refugees and transnationalism: the experience of Bosnians and Eritreans in Europe. Journal of Ethnic and Migration Studies, 27, 615-634.

Amposah, M. D. (2009). An exploration of refugee integration: A case study of Ganfoso refugee camp, Ghana. (Doctoral dissertation).

Anarfi, J. K. (2010). Immigration into Ghana Since 1990. Regional Institute for Population Studies (RIPS) http://www.oecd.org/ countries/ghana/46733734.pdf. Accessed 22 May 2018.

Dowding, K. (2008). Agency and structure: Interpreting power relationships. Journal of Power, 1(1), 21-36. https://doi.org/10. 1080/17540290801943380.

Easby, A. (2016). Indigenous Research Methodologies. Final Report (Global Thematic Review on Training in Community-Based Research). PRIA and University of Victoria.

Frelick, B. (1997). The year in review. World Refugee Survey, 1997 (p. 14). US Committee for Refugees.

Giddens, A. (1984). The constitution of society: Outline of the theory of structuration. Cambridge: Polity Press.

Giddens, A. (1991). The self: Ontological security and the existential anxiety. In A. Giddens, Modernity and selfidentity: Self and society in the late modern age (pp. 35-42). California: Stanford University Press.

Healey, R. L. (2006). Asylum seekers and refugees: A structuration theory analysis of their experiences in the UK. Population, Space and Place, 12(4), 257-271. https://doi.org/10.1002/psp.412.

Hélot, C., \& Young, A. (2008). Parent-teacher partnerships: Co-constructing knowledge about languages and cultures in a French primary school. In C. Kenner, \& T. Hickey (Eds.), Multilingual Europe, diversity and learning (pp. 89-95). Stoke on Trent: Trentham Books.

Hay, C. (2009). 'King Canute and the "Problem" of Structure and Agency: On Times, Tides and Heresthetics'. Political Studies, 57(2), 260-79.

Inyundele, A. (n.d.) Critique of Antony Giddens https://www.academia.edu/12077118/CRITIQUE_OF_ANTONY_GIDDENS. Accessed 15 May 2019.

Jacobsen, K. (2001). The forgotten solution: Local integration for refugees in developing countries (New Issues in Refugee Research, PDES Working Paper No. 45). UN High Commissioner for Refugees (UNHCR). http://www.unhcr.org/cgibin/ texis/vtx/search?page=search\&docid=3b7d24059\&query=NewlssuesinRefugeeResearch. Accessed 11 Aug 2020.

Kpatindé, F. (2006). A tale of two camps: Bustling Buduburam and quiet Ganfoso. UNHCR. http://www.unhcr.org/news/latest/2 006/7/44c7783e4/tale-camps-bustling-buduburam-quietGanfoso.html. Accessed 16 May 2016.

Little, D. (2012). Giddens on Agents and Structures. Understanding Society. https://understandingsociety.blogspot.com/2012/ 05/giddens-on-agents-and-structures.html.. Accessed 14 Aug 2020. 
Ma, L. (2010). Theory and education: A case of structuration theory. Bloomington: Indiana University.

Marnitz, G. (2014). Creating a multilingual classroom environment for monolingual and multilingual children in Scotland. Journal on Pedagogy and Education, Special Issue. http://netla.hi.is/serrit/2014/diversity_in_education/005.pdf. Accessed 20 Aug 2016.

MGCSP (2015). National School Feeding Policy. Ministry of Gender, Children and Social Protection, Republic of Ghana. http:// mogcsp.gov.gh/mdocs-posts/national-school-feeding-policy/. Accessed 25 June 2018.

Naidoo, L. (2010). A Structuration Theory Analysis of the Refugee Action Support Program in Greater Western Sydney. Australian Journal of Teacher Education, 34 (4), Article 5. http://ro.ecu.edu.au/ajte/vol34/iss4/5. Accessed 23 Sept 2020.

Richmond, A. H. (1993). Reactive migration: Sociological perspective on refugee movements. Journal of Refugee Studies, 6, 7-24.

Schmidt, C (2016). Including refugee students in national education systems. Part 1. Global Partnership for Education. https:// www.globalpartnership.org/blog/including-refugee-students-national-education-systems-part-1. Accessed 17 Aug 2020.

Sewell Jr., W. H. (1992). A theory of structure: Duality, agency, and transformation. The American Journal of Sociology, 98(1), 1-29.

Tucker, M. (1998). On the relations between seen objects and components of potential actions. Journal of Experimental Psychology, 24(3), 830-846. https://doi.org/10.1037/0096-1523.24.3.830.

Turner, H. J. (1986). The theory of structuration reviewed work(s): The constitution of society: Outline of the theory of structuration, Anthony Giddens. American Journal of Sociology, 91(4), 969-977.

UNHCR (2012). Submission by the United Nation High Commissioner for Refugees (UNHCR) to the Office of the High Commissioner for Human Rights' Compilation Report - Universal Periodic Review, Ghana. UN High Commissioner for Refugees (UNHCR). http://www.refworld.org/docid/4f7867ff2.html. Accessed 18 Sept 2016.

UNHCR. (2013). Displacement: The 21st century challenge. UNHCR Global Trends 2012. https://www.refworld.org/docid/51c16 9d84.html. Accessed 11 Oct 2015

UNHCR (2014). UNHCR Public Health 2014 Annual Global Overview. UN High Commissioner for Refugees (UNHCR).

Varelas, M., Settlage, J., \& Mensah, M. F. (2015). Explorations of the structure-agency dialectic as a tool for framing equity in science education. Journal of Research in Science Teaching, 52(4), 439-447. https://doi.org/10.1002/tea.21230.

Valtonen, K. (2004). From the margin to the mainstream: Conceptualising refugee settlement processes. Journal of Refugee Studies, 17(1), 70-96. https://doi.org/10.1093/jrs/17.1.70

\section{Publisher's Note}

Springer Nature remains neutral with regard to jurisdictional claims in published maps and institutional affiliations.

\section{Submit your manuscript to a SpringerOpen ${ }^{\circ}$ journal and benefit from:}

- Convenient online submission

- Rigorous peer review

- Open access: articles freely available online

- High visibility within the field

- Retaining the copyright to your article

Submit your next manuscript at $\boldsymbol{\nabla}$ springeropen.com 